\title{
TRADITION AND CONCEPTUAL DYNAMICS ACCORDING TO AN INFERENTIALIST THEORY OF MEANING
}

\section{ARIEL FURSTENBERG}

Hebrew University of Jerusalem

\begin{abstract}
In this article I develop a conceptual dynamical account from an inferentialist theory of meaning and content; thus illuminating the connection between conceptual dynamics and tradition. The inferentialist theory taken into account here is that of Robert Brandom. While expanding on Brandom's notion of scorekeeping, I claim that insufficiency, and sometimes even inability, to differentiate and navigate between past heritage and present discourse is of the essence of highly traditional discourses; creating a unique type of conceptual dynamics which is commonplace mainly within religious traditional discourses. This claim is supported by a case study from a Jewish traditional discourse.
\end{abstract}

\section{INTRODUCTION}

The goal of this paper is to illuminate and develop the connection between tradition and conceptual dynamics from an inferentialist theory of meaning. The inferentialist theory taken into account here is that of Robert Brandom, and the tradition exemplified here is that of the Jewish tradition as expressed especially in the Babylonian Talmud. The paper focuses at first on the normative structure that lies beneath Brandom's theory of meaning through the notions of inferentialism and conceptual content. By articulating the normative structure we can make explicit the types of conceptual dynamics that are natural and justified within this normative structure. Given these dynamics, we are ready, in the second half of the paper, to articulate our general notion of tradition, including religious tradition. According to the inferentialist perspective there is a deep connection between tradition and dynamics and it is hard to talk of the former without understanding the latter. Although the 
deep connection between tradition and dynamics is general and need not be limited to Jewish tradition, it is expressed in several ways in the Babylonian Talmud and is a unique contribution of it.

In order to fully understand the tri-polar-connection between theories of meaning, conceptual dynamics and tradition let me say a few introductory words regarding the first two. Philosophies of natural language deal with a vast number of issues such as: formal grammar, syntax, proper names, anaphora, reference and meaning, to name only a few. Their span of interest ranges from the boundaries of linguistics, trying to understand the various linguistic mechanisms implicit in natural language, to the more general metaphysical exploration of the relation or lack thereof between language and reality. However, there is one thing one might expect in such an account but is generally lacking, and that is -dynamics. Many of these philosophies provide none or little account of the dynamics by which the language changes or evolves. To a great extent, current philosophical literature treats cultures of discourse as rigid, static frameworks, with little attention given to the modes of production and modification of these frameworks. Wittgenstein, for example, dealt mainly with characterizing the language-game and not with the coming into being of a language-game or the possibility of change and transformation from one language-game to another. ${ }^{1}$ Even in the case of Putnam and Kripke who give some account of conceptual change over time and try to articulate what gives a concept its identity e.g., what makes a concept at one point in time identical to itself at another point in time - they refer to it as a problem that has to be solved, ${ }^{2}$ not as a dynamical phenomenon to be described and explained within a certain normative background.

My first claim is that even though many philosophies of language do not deal explicitly with evolution and modification of the conceptual system, in many cases evolution and modification are implicit in these philosophies, and one can actually expose and reveal them. Thus, different philosophies support different accounts of dynamics of change. Not every form of evolution, modification and coming into being of

${ }^{1}$ In a few places Wittgenstein deals with the possibility of change of a linguistic framework, but these are the exception. For example: Investigations 23, 60-61, 64, 115, 206, 492; On Certainty 63, 65, 92-99, 256, 262, 336, 652; Wittgenstein 1980: 15, (44), 48.

${ }^{2}$ See for example Putam's account on the identity of concepts (such as temperature) which is presented as an incommensurability and translation problem between speakers of different generations (Putnam 1981: 113-119). 
a language or a conceptual system fits every philosophy of language. This is a linkage I want to stress between natural language philosophy and dynamics. More precisely, I think there is a link between one's theory of meaning - i.e., one's theory of conceptual meaning: how do concepts acquire their meaning and what is the normative structure that brings this about? - and the dynamics of change and modification that is natural to such a linguistic system.

One way of looking at it is as follows: A normative structure creates a web of commitments and constraints that bind the speaker who speaks from within it. The range of possibilities of modification and evolution of a conceptual system within the normative structure depends on this set of constraints and commitments that bind the speaker. ${ }^{3}$ In order to expose the dynamical aspect underlying changes from an earlier conception to a later radically different one, this dependence has to be explicated; the effect that the commitments and constraints of the normative structure have on the evolutionary trajectory of a conception has to be articulated. The normative structures that interest us in this paper are normative structures that are implicit in theories of meaning. Thus I open with the question: what kinds of conceptual dynamics are natural to certain theories of meaning, and specifically to an inferentialist theory of meaning?

In the following section (section 2) I will make a brief sketch of Brandom's Pragmatism focusing on the ideas of inferentialism, conceptual content and meaning. Following these principles, I will investigate the dynamics of conceptual change that are natural to the Brandomian normative structure. Section 3 analyzes two dynamic sorts which are embedded in the Brandomian normative structure itself and can be considered defining features of it. In section 4 we are ready to tackle the issue of tradition and the dynamic that results from traditional commitment from an inferentialist Brandomian perspective. Usually we think of tradition as basically standing in opposition to dynamics; however, I will stress the essential role tradition can have in creating dynamics. Here I go beyond Brandom's account of tradition; in the core of Brandom's account the present speaker and his past heritage

\footnotetext{
${ }^{3}$ It is important to maintain and be aware of the difference between conceptual change within a normative structure and a change of the normative structure itself (see Fisch \& Benbaji 2011). This difference does not mean that one cannot in certain scenarios begin with a thoughtful change of a conceptual system within a normative structure which results in a change of the normative structure itself.
} 
are well defined entities that can have various relationships which are expressed by the type of navigation between these distinct entities. In contrast, my main claim is that in traditional discourse the very ability to differentiate and navigate between these entities, namely the speaker and her past heritage, comes in question. This inability to differentiate and to navigate between past and present is of the essence of the traditional discourse, and it creates a special type of conceptual dynamics which is commonplace within such traditional discourses (named here: traditiontype dynamics). Section 5 is a concise exposition of a religious traditional discourse, that of the Jewish Babylonian Talmud, with a fairly detailed example of a tradition-type dynamics.

\section{BRANDOM'S THEORY OF MEANING: INFERENTIALISM}

Three dimensions are involved in understanding what it means to grasp a concept: inferential, normative and social. ${ }^{4}$ While they are all interconnected, the inferential dimension is a basic structural one; and indeed Brandom defines conceptual content through its inferential role: 'to be conceptually contentful in the most basic sense is to play a role as premise and conclusion in inferences' (Brandom 2002: 94). Although inferentialism defines a structure it is not solely a logical or syntactic one, but it involves also material rules of inference. ${ }^{5}$ For example, the sentence 'Today is Wednesday' implies that 'Tomorrow will be Thursday'. These types of inferences are considered material inferences. In these inferences neither the premises nor the conclusions employ logical concepts; therefore it seems appropriate to distinguish them from inferences whose correctness depends only on logical form. ${ }^{6}$

A word becomes a concept only if it acquires a role in reasoning. Situating concepts in an inferential structure of premises and conclusions occurs naturally, according to Brandom, in the social framework of making claims and giving and asking for reasons. '[F] or a response to have conceptual content is just for it to play a role in the inferential game of making claims and giving and asking for reasons' (Brandom 2000: 48).

This approach results in the reversal of the traditional relationship between representational properties and inferential properties:

\footnotetext{
${ }^{4}$ An account of the historical-conceptual evolution of these dimensions in Brandom 2002 (a brief analysis: ibid., pp. 21-32).

${ }^{5}$ Brandom 1994: $97 \mathrm{ff}$.

${ }^{6}$ Brandom 1994: 98.
} 
The idea that one can first fix the meaning or content of premises and conclusions, and only then worry about inferential relations among them, is characteristic of traditional and twentieth-century empiricism. This implicit semantic commitment is questioned, however, by the rationalist tradition in semantics, which sees issues of what is a reason for what as essential to the identity and individuation of the conceptual contents that stand in those inferential relations (Brandom 2002: 4). ${ }^{7}$

These inferentialists seek to define representational properties in terms of inferential ones, which must accordingly be capable of being understood antecedently. They start with a notion of content as a matter of what is a reason for what and understand truth and representation as features of ideas that are not only manifested in, but conferred by their role in reasoning. This is the tradition that Sellars inherits and builds on by developing a notion of conceptual content that starts with inferential roles (Brandom 1994: 94). ${ }^{8}$

According to Brandom, ${ }^{9}$ when one utters a sentence and thereby makes an assertion, one is committing oneself to defend that assertion against whatever objection or challenge might be raised by a hearer. The defence would take the form of giving reasons in support of that assertion, typically by inferring it from some other sentence (whose uttering might not be so readily open to challenge).$^{10}$ In making the assertion one also confers on oneself the entitlement to make further inferences from it. In this way one reveals the web ${ }^{11}$ of material inferences that his assertions are imbedded in. This process of revelation through the social game of giving and asking for reasons is what Brandom calls making it explicit, i.e., making the implicit web of material inferences explicit. ${ }^{12}$

${ }^{7}$ One should note that 'inference' is an expression that belongs to pragmatics, to the use of language; whereas 'inferential relation' belongs more to semantics (see Clausen 2004: 80).

${ }^{8}$ Objectivity is a central notion, which I do not go into in this context, related to truth and representation. One can find a detailed discussion on Brandom's account of 'objectivity' in Stout 2002 and Clausen 2004.

${ }_{9}$ Brandom 1994; 2000.

${ }^{10}$ MacFarlane 2003.

11 The 'web' metaphor and its 'relatives' are used by many (Quine, Davidson and Hesse, to name only a few). Although Brandom scarcely uses it (e.g., Brandom 1994: 90) I find it a useful metaphor and will use it in what follows.

${ }^{12}$ What we are missing in Brandom's narrative is an account of why is 'giving and asking for reasons' the given social practice. For some justification see Fisch \& Benbaji's (2011) account of their fictitious 'Brandomian Doubter'. 
Brandom's pragmatism is radical in the sense that meaning is a result of the position held by a concept or an assertion in the web of inferences. Concepts and assertions acquire their meaning solely by their role within the web of inferences. Thus one central consequence is that identical concepts or assertions can have different meanings in the mouths of different speakers, as one speaker's web of inferences is different from another. One way of explaining these differences is that they are created by the collateral commitments that serve in the speaker's background. For example, a speaker utters the sentence: 'you see the librarian; she is wearing a red sweater.' In making herself explicit and positioning the utterance in her web of inferences the speaker might say things like 'red is a colour', 'the librarian is not wearing a green sweater', etc. But let's assume for the moment that the speaker belongs to a religious group in which she is committed to certain views. In her making it explicit she might add inferences of a different sort, such as: 'she is wearing red; hence she is not modest'; or 'she is more vulnerable to the "evil-eye". A different set of background commitments usually means a different inferential web, constituting the subtext underlying meaning and entitling the speaker to continue in her tracks.

Brandom's philosophy does not limit the speaker to a fixed set of commitments and inferences; the only normative requirement is that the commitments and inferences the speaker holds constitute a consistent unit. ${ }^{13}$ But how is this normative requirement achieved? It is achieved in practice mainly through the abovementioned social game of giving and asking for reasons (which is also termed the Socratic Method) and by making implicit inferential commitments explicit:

Formulating as an explicit claim the inferential commitment implicit in the content brings it out into the open as liable to challenges and demands for justification, just as with any assertion. In this way explicit expression plays an elucidating role, functioning to groom and improve our inferential commitments, and so our conceptual contents ... (Brandom 2000: 71, my emphasis)

Socratic method [as introduced by Sellars] is a way of bringing our practices under rational control by expressing them explicitly in a form in which they can be confronted with objections and alternatives, a form in which they can be exhibited as the conclusions of inferences seeking

${ }^{13} \mathrm{~A}$ basic feature of this inferentialist account is a certain type of holism (See Brandom 2000: 15-16, 167; Brandom 1994: 89-91, 477-482, 587-588; Fodor \& LePore 2001). 
to justify them on the basis of premises advanced as reasons, and as premises in further inferences exploring the consequences of accepting them. (Brandom 2000: 56, my emphasis)

Making it explicit and giving and asking for reasons is the process of finding out and elucidating one's inferential web. Beyond the straightforward challenge and demand for justification, the speaker wants to avoid inconsistencies; a situation in which some listener points out to her during the game of giving and asking for reasons that what she infers at one part of her inferential web contradicts an inference at a different part of the web. In other words, the speaker should be able to produce justifications - that is, give adequate reasons - for thinking that the sentence she utters is true, whenever her assertions are challenged. That includes not falling into inconsistent inferences she cannot defend and justify. Thus, the basic normative requirement is that the commitments and inferences the speaker holds constitute a consistent unit.

\section{STRIVING FOR A STANCE: BRANDOMIAN DYNAMICS}

The norms constitutive of this practice of talking and asserting, as I have described them following Brandom, do not include an obligation to hold on to one's previous commitments or to agree with one's fellow speaker's commitments. ${ }^{14}$ Following this, a speaker can definitely give up a commitment or modify one, or change her web of inferences either because of some deficiency in her web or just because she feels like giving up one commitment and choosing another. Our only linguistic normative requirement is that she be able to defend her current web of inferences and demonstrate its consistency.

At this point, I make explicit two types of dynamics which are implicit in Brandom's Theory of Meaning. It is helpful to define these dynamics in relation to the type and level of constraints the normative structure imposes on change and modification. The first kind of dynamic is as follows: a speaker can be challenged by a listener, as a result of making certain aspects of her web of inferences explicit, claiming that there is some inconsistency in her web. For example, from a certain set of commitments consequences arise that the speaker was not aware of, and now that they became explicit she is facing an inconsistency which she cannot justify; she is therefore forced to modify her web of inferences.

${ }^{14}$ Stout 2007: 25-26. 
In such a case the constraints regarding change and modification seem to be of infinite force, i.e., the speaker is executing a modification in which the need for it was determined already implicitly in the speaker's web of inferences and set of commitments. The speaker cannot ignore the need for change and modification. Although the results of the modification are not determined and there may well be many possible results that are faithful to one's set of commitments, the actual need for change is determined. The need for change and modification is a result of one's given articulation of her web of inferences and set of commitments. I will term this kind of dynamic: determined-type dynamic.

Let's imagine an ideal case in which a speaker's web of inferences is totally explicit and it has no shady parts to it. Brandom, of course, does not think this is possible, but he writes:

Such a system is an idealization, because all of its concepts would already be out in the open; none remaining hidden, to be revealed only by drawing conclusions from premises that have never been conjoined before, following out unexplored lines of reasoning, drawing consequences one was not previously aware one would be entitled or committed to by some set of premises. In short, this would be a case where Socratic reflection, making implicit commitments explicit and examining their consequences and possible justifications, would never motivate one to alter contents or commitments. Such complete transparency of commitment and entitlement is in some sense an ideal projected by the sort of Socratic practice that finds current contents and commitments wanting by confronting them with one another, pointing out inferential features of each of which we were unaware (Brandom 2000: 72-73, my emphasis).

In a way the most basic aspiration of a Brandomian speaker is reaching this transparency, in reaching stability; to speak from within a stance. This goal is a static one. If the idealization described above was realized and all concepts would have been 'out in the open' with the inferential web totally explicit, there would have been no altering of contents or commitments of the dynamical type described above (determined-type dynamic). This idealization emphasizes Brandom's stable and static aspirations. It is interesting to note however that the process of achieving this static goal is a very dynamic one. Therefore the idealized goal stands in contrast to the actual practice of the Brandomian speaker which is very much anti-static; almost every utterance amongst speakers results 
in re-organization of one's commitments and entitlements. The very act of making it explicit results frequently in the awareness of the need for justification which cannot be achieved by more explication and must be done in many cases by change and modification. This is the determinedtype dynamic embedded in the Brandomian normative structure in which the constraints for performing change are infinite.

Since the Brandomian normative requirement is that a speaker will be able to defend her current web of inferences and demonstrate its consistency, it follows that a speaker can change her web of inferences just because she feels like giving up one commitment and choosing another, as long as she is able to still demonstrate its consistency. Here modification is a result of the speaker's free will and her choice of commitments which might be independent of her previous set of commitments. In this case, the previous web of inferences and set of commitments held by the speaker pose no constraint on the act of modification. The speaker abandons one web of inferences and set of commitments and chooses a different one; the constraints of the previous web of inferences and set of commitments are zero. Holding to the Brandomian normative structure based on his theory of meaning makes such a dynamic a possible continuation of such a structure. This is a free-type dynamic embedded in the Brandomian structure in which the constraints for performing change are zero. Of course one has many other constraints resulting from other normative spheres, as social and psychological ones; however in this paper the focus is solely on the normative structure that is at the basis of Brandom's theory of meaning.

One reason for analyzing the Brandomian case is that in virtue of Brandom's radical pragmatism it exemplifies nicely the two extremely opposing levels of constraint; determined-type dynamic with an infinite level of constraint, and free-type dynamic with a zero level of constraint. However, other philosophies of language and theories of meaning might exhibit midway levels of constraint. For example, a more semantic theory which doesn't hold like Brandom that 'semantics must answer [only] to pragmatics' would show a midway level of constraints, since the constraints for modification would mainly be a result of some sort of 'semantic kernel'. ${ }^{15}$

${ }^{15}$ For such an approach see examples in Lycan 2000. 


\section{TRADITION AS A SOURCE OF MODIFICATION}

On a very basic level tradition and conceptual dynamics are connected since they both allegedly deal with the relation between past and present. Brandom in his Tales of the Mighty Dead classifies several possible types of relations between a speaker and her past tradition. ${ }^{16}$ However all of these types express ways of articulating the past from within a stance, from within the present speaker's given web of inferences and commitments. What Brandom is missing is an account of how the past tradition affects one's given web of inferences and commitments; not only how one's given web of inferences is justified through one's past tradition. What role might past tradition have in the dynamics of one's present (natural/religious) language? In order to approach this question let us look at the rather extreme case and ask: what does it mean for a speaker to be part of a highly traditional discursive culture? To answer this we must emphasize a central feature of traditional discourse by mentioning one more important Brandomian notion - the notion of scorekeeping.

In the process of giving and asking for reasons in which the speaker explicates her web of inferences, the listener 'keeps score' of the speaker's commitments, entitlements and inferences. Scorekeeping includes comparing the speaker's web of commitments, entitlements and inferences to one's own, and being able to navigate from one perspective to another, from the speaker's perspective to one's own. Scorekeeping is an essential part of communicating with each other, ${ }^{17}$ and language creates many techniques in order to make it possible (e.g., anaphora and pronouns). ${ }^{18}$

The paradigm of communication as joint possession of some common thing is relinquished in favor of - or modified in the direction of a paradigm of communication as a kind of cooperation in practice ... What is shared is a capacity to navigate and traverse differences in points of view, to specify contents from different points of view. (Brandom 1994: 485)

In this view content cannot be detached from perspective; therefore in

${ }^{16}$ Brandom 2002, Introduction and pp. 94-118.

17 Remember that in the Brandomian account same concepts or assertions can have different meanings in the mouths of different speakers, as one speaker's web of inferences is different from another. Scorekeeping assures communication in the face of this consequence.

18 Brandom 1994: 486-488, 588-592. Rouse 2002: 202. 
communication when content is exchanged it comes with an inferential perspective. This is done by constant navigation between the different perspectives and their contents, and keeping score of the perspectival content. Andrea Clausen elaborates:

[C]ommunication is not based upon shared sets of inferences. The inferential significances which different interlocutors associate with a claiming need not have any inferences in common ... [T] he traditional model of communication as conveyance of information from a sender to a recipient can no longer be sustained. Brandom rather understands communication as navigation between different perspectives ... To say that content is common to different assertions is all right provided that this only means that it is constituted by different interlocutors, not that mastering content has to be presupposed in successful communication. (Clausen 2004: 94-95)

Keeping score and navigating between different perspectives is done in many cases by expressing a fellow-speaker's assertion with my own commitments inserted in it. In that way I know and express my own standpoint despite the fact that I'm conveying the fellow-speaker's claim. For example, Jason asserts the following: 'I believe that the receiver of the Ten Commandments from heaven invented a way of turning rock into water.' Now let's assume that I do not believe in the Ten Commandments being a heavenly creation, but I still want to present Jason's assertion. I could do that by inserting my own beliefs within Jason's assertion. And that is possible by differentiating between what we are talking about and what we are asserting. ${ }^{19}$ Here Brandom uses the de dicto and de re ascriptions for his own purposes and expresses this idea by showing how one converts a de dicto ascription into a de re ascription..$^{20}$ Jason's assertion in my mouth would sound something like: 'Jason believes of the author of the Ten Commandments that he invented a way of turning rock into water. ${ }^{21}$ In this way I could present Jason's assertion without committing myself to beliefs I do not hold. This is a kind of navigating method: I hold to my own beliefs (i.e., Moses is the author of the Ten Commandments and did not receive them from heaven) while trying to express my fellow speaker's assertion (i.e., Moses invented a way of

\footnotetext{
19 Brandom 1994: 499-508. Examples: Brandom 1994: 500-505, 588-589.

${ }^{20}$ Brandom 1994: 502.

${ }^{21}$ This is considered in Brandom's terms a de re ascription (Brandom 1994: 499-508, 588-589).
} 
turning rock into water). Keeping track of this sort is of the essence of scorekeeping. ${ }^{22}$

Nevertheless, from a Brandomian perspective, Scorekeeping is not only an activity that could be carried out by speakers living and talking with each other; it could be carried out even by a speaker who is communicating, in a sense, with the past, with his past tradition. ${ }^{23}$ Therefore, I could express someone else's claim even if he is a speaker from my past tradition, without accepting all his commitments and by inserting my own commitments within his assertions, in the same manner we just saw with present speakers (like in Jason's case).

Here I come to my main point. One of the essential aspects of scorekeeping is that different speakers represent separate identities; they stand apart from each other and one can navigate between these separate identities. Now, what happens when navigation between speakers is not fully expressed, i.e., when the differentiation between speakers is not clear and not fully realized? What is the meaning of scorekeeping when the differentiating wall between speakers falls? These are general questions about scorekeeping but their importance lies mainly with regard to tradition; such scenarios are commonplace in highly traditional discourses, since one of the essences of tradition is the collapsing of the walls differentiating between past and present speakers. Consequently, these scenarios can result in a unique dynamic, as we shall see below.

My account of one's interaction with past tradition is different than Brandom's. Brandom sees the present speaker and her tradition as two defined identities between which the present speaker can navigate. In his account these are two differentiated entities even in a case in which the present speaker's access to the past inferential web is partial because of her limited ability to play with the past the game of giving and asking for reasons.

To make my point clear let's look at a certain type of scorekeeping which is a reverse picture of the above example. In the same way I can express someone else's claim with my own commitments inserted in it (as in Jason's case), I can make my own assertion but with someone else's commitments inserted in it. This is done sometimes by adding the words 'so-called' before the fellow-speaker's expression or by adding 'scarequotes' to that expression. For example:

22 Stout 2007: 24-25.

${ }^{23}$ For an analysis of different models of scorekeeping past heritage, see Brandom 2002. 
- Speaker A says: 'David, the righteous king, wrote the book of Psalms'.

- Speaker B replies: 'That so-called 'righteous king' stole Bat-Sheva and sent her husband to his death'

From B's perspective a king who steals a woman and sends her husband to die can hardly be called a righteous king. However, she is inserting speaker A's expression within her own assertion and she is supposedly using speaker A's commitment. The technique of differentiating between what the two speakers are committed to is by saying the words 'socalled' (or by adding the scare quotes). By doing so one underscores the commitments one does not agree with and does not take responsibility for. This can be considered complementary or dual to the de re ascription. ${ }^{24}$

I want to take this description further and claim that this structure is a good platform for a dynamic of change and evolution resulting from past expressions and commitments. Let's imagine a case in which A's expression is inserted within B's sentence (as appears above), but this time without a differentiating technique like the term 'so-called' or without the scare quotes. When does such an imaginary case happen? This can happen (and it is not imaginary at all) in a highly traditional discursive community in which parts of past expressions are embedded within current discourse without a differentiating technique. It is as if the 'so-called' phrase or the scare quotes fell at some point in the process of embedding past expressions into current discourse. In such a case we might say that B is not adopting A's commitment, although A's words appear without differentiation as part of B's expression. In the above example the result would look like this (in the mouth of speaker B): 'That righteous king stole Bat-Sheva and sent her husband to his death.' Now, the speaker's normative obligation is to make sense and embed this sentence within her web of inferences; trying to make sense of this sentence could introduce an interesting dynamic, with the end result being neither A's perspective nor B's perspective. This is an extreme example but the idea is clear; the speaker's task (B's task) is to take her sentence, containing also A's expression embedded in it without any technique differentiating between them, and make explicit its inferential web. Making it explicit might result in modification of the various concepts and commitments constituting this assertion (e.g., 'righteous', 'stole'), resulting in a new inferential web.

${ }^{24}$ Brandom 1994: 545-547, 588-590. 
In the light of this, I think it is useful to articulate one of the core characteristics of traditional discourse as a discourse which embeds expressions from one's past heritage into one's present language with varying levels of commitment; however with no tools (or - with low level tools) differentiating between past and present speakers; with no real ability to navigate between perspectives of past and present speakers. The moment the wall differentiating between speakers disappears and it stops being clear what belongs to A and what belongs to $\mathrm{B}$, is a good starting point for innovation. This is the point where a speaker has to re-assess her commitments and put her web of inferences together again. Since this process is commonplace in highly traditional discourses we will term this process: tradition-type dynamic. This dynamic is highly useful in analyzing the evolutionary conceptual process occurring in discourses in which past heritage expressions play a central role in current language while past/present speaker identities are not fully differentiated. ${ }^{25}$

The deep connection between tradition and dynamics is apparent in highly traditional discourses. In the following section I focus on this inferentialist dynamic as it is expressed within the highly traditional discourse of the Babylonian Talmud, in which the interplay between tradition and conceptual dynamics has an essential part in its unique character.

\section{TRADITION-TYPE DYNAMIC WITHIN THE BABYLONIAN TALMUDIC DISCOURSE}

A tradition-type dynamic is actually a spectrum of dynamics in which the level of identification with the commitments attached to a fellowspeaker's expression from the past can vary from case to case. The Jewish Babylonian Talmudic discourse can be considered a highly traditional one; its discourse is dialogical in nature spanning a period of more than 200 years (starting at about 200AD). The interlocutors are rabbinic sages of the Talmudic period called the amoraic rabbis. The Talmudic discussion

${ }^{25}$ The deep ambivalence that is essential as the base for real normative transformation according to Fisch \& Benbaji (2011) can be created not only by a close and reliable critic as they claim, but also by this complex relationship with tradition. I think that in certain cases tradition, especially in a religious context, goes much deeper into one's self-identity than even a trustworthy critic, since tradition has in certain cases a strong gripping power. 
is centred around the canonical tannaitic text, called the Mishna, which is a redaction of Jewish oral traditions compiled at around 220AD. The typical Talmudic discussion starts with what seems to be a commentary on a certain Mishna deliberating on some Jewish law (halakha). From there onward the discussion branches and expands into a vast number of possible topics, mainly in Jewish law, but not only, also philosophical, exegetical, physical, mathematical and medical. During the process of deliberation the Talmudic interlocutors often refer to earlier texts from past heritage either from the tanaitic period or from the earlier biblical period.

The Talmudic speaker, in many cases, practically chooses ${ }^{26}$ at every stage of the discourse the type and level of commitment towards the past heritage he wants to exhibit at that stage. He chooses whether he is committed to just using the same words that appeared earlier, or maybe to the concepts behind these words or maybe even to the earlier conceptions containing these concepts. This defines the framework in which the Talmudic speaker will conduct his argumentations at that stage. ${ }^{27}$

One type of Talmudic commitment towards the past is a commitment to rulings and cases from past heritage. As mentioned, this might be a commitment to the rules and cases themselves, to the concepts or conceptions behind them or just to the wording of these rules and cases. Being committed to past heritage expressions, sometimes just to snippets of it, mainly means that these expressions become part of the ongoing later discourse; but in what sense do they integrate into later discourse? How do they influence the discourse? The answer lies in the traditiontype dynamic. In many cases the wall differentiating between past and present identities collapses and there is no real navigation between present and past speakers. What starts in the Talmudic discourse as genuine scorekeeping with multi-dimensional and multi-generational navigational moves between present and past identities, deflates, many times, as a result of the traditional force into present assertions with past locutions embedded in them, nonetheless with no differentiating technique. Thus what we observe is that past heritage integrates into

${ }^{26}$ I use the term 'choose' although it is not always clear whether it is an aware or nonaware choice.

${ }^{27}$ Moreover, it is interesting to note the Talmudic phenomenon of changing the type of commitment towards past heritage from one stage of the discussion to another. This seems to be explained best by holding on to a Brandomian theory of meaning with a freetype dynamic. 
later thought in indirect and sometimes unexpected ways. E.g., the later generation (amoraim) are portrayed as employing an earlier generation's (tannaitic) term without adopting the earlier generation's (tannaitic) commitment that went along with it; nevertheless without employing a differentiating technique, resulting in a change in the inferential significance of the term and in a novel later generation (amoraic) perspective. The final result is neither an expression of the later speaker's set of commitments and web of inferences, nor is it an expression of the earlier layer. What results is a novel set of commitments and inferential web. The exact process depends of course on the initial commitment to the past, on the one hand, and on the other hand on the level of differentiation between past expressions and later assertions exhibited by later speakers and their ability to navigate between the different perspectives. $^{28}$

As an example let's look at the following Talmudic issue, that of measurement and division; is it possible to measure two quantities and conclude that they are exactly the same size? Or is it possible to divide a quantity exactly into half? These possibilities are termed by the earlier tanaitic generations as 'half $\&$ half situations. It is important to point out that there are several rulings and cases in the tanaitic literature in which this is the underlying possibility. For example: 'The combination of pure [sheep's] wool and pure linen is forbidden under the law of Mixtures of Diverse Species ... If camel's hair and sheep's wool have been mixed together and the majority is from the camel it is permitted [to be mixed with linen]; if the majority is from the sheep's wool it is prohibited; if they are in equal parts ('half and half) - it is prohibited.' (Mishna, kilayim 9:1). Another example: 'If a young pigeon is found between two dovecots and is nearer to one, it belongs to the owner of this dovecot, and if nearer to the other it belongs to the other; and if it is at a like distance from either ('half and half) - they share it' (Mishna, Baba Batra 2:6). It seems that the tanaitic sages raise no problem regarding the possibility of ' $h a l f$ and half; it's a possibility like any other possibility which the sages have to deal with and give their ruling.

However, discontent with the possibility of 'half and half' arises when we get to the later amoraic period. It starts as a vague disapproval of the 'half and half' possibility and is developed through several stages of

${ }^{28}$ This ability might be a result of the normative traditional constraints on the one hand or a matter of choice, on the other hand. 
amoraic deliberation which I will omit in this context. The final stage culminates as a response to a certain Mishna ${ }^{29}$ which discusses the case of 'first born' in which twin male sheep were born simultaneously, and their heads came out at exactly the same time. R. Yose from Galilee rules that both sheep are considered 'first born', and they both belong to the Priest in accordance to the rule of 'first born'. On the other hand, the Rabbis ${ }^{30}$ in the mishna reply and say: 'that's impossible; hence one belongs to the priest and one stays with the Israelite owner.' The Talmud takes this disagreement to be an extension of the issue of 'half and half, however with a slightly different angle which includes both simultaneity and exact measurement and division: is it possible to have exact simultaneity and is it possible to ascertain exact precision in measurement and division ${ }^{31}$

The disagreement in the Mishna is situated within the context of a natural random process, namely that of giving birth. The Talmud continues the analysis and raises the question as to the possibility of simultaneity and 'half and half situations within a different context that of human action in which human intention is involved in making something simultaneous and precise and it is not just a result of a natural random process. Regarding the Rabbis' perspective, the Talmud performs a scorekeeping move and states the following: 'The Rabbis hold that it is [ontologically] impossible to ascertain exact precision and simultaneity in natural processes.' This perspective is inferred from what the Rabbis said in the above Mishna, from the words 'that's impossible' - that it is impossible that the two sheep were born exactly at the same time. This conclusion has been generalized to mean an ontological impossibility although the tanaitic Rabbis have most probably just meant it as a technical impossibility.

In this move real perspectival scorekeeping seems to be deflated, as the words from the Mishna are used and taken to express the later Talmudic perspective and not the earlier tanaitic perspective. However, the apparent scorekeeping effort goes on and the Talmud asks regarding

${ }^{29}$ In Babylonian Talmud, tractate Bechorot 17a.

30 The 'Rabbis' in this Mishna are an anonymous collective group; however they denote a viewpoint, which will be referred to henceforth with capital R ('Rabbis').

${ }^{31}$ Note that the Talmud extends the idea of simultaneity to any attempt to carry out an exact measurement, especially with regard to the cases termed 'half \& half'. According to the Talmud, the ability (or inability) to measure or create a situation of simultaneous events is the same ability (or inability) to measure or create an exact 'half \& half' situation. This is an interesting extension equating space and time. 
the Rabbis of the Mishna: 'What is their view with regard to human [intentional] actions?' As the Talmud inferred above, it is ontologically impossible to ascertain exact precision and simultaneity in natural processes according to the Rabbis of the Mishna; however is it possible to ascertain exact precision when measurement and division are conducted by means of human intention, according to them?

The Talmud in this deliberative process exhibits commitment to earlier tanaitic rulings and cases and tries to deduce from them an answer to the question the Talmud is interested in of human ability to create an exact 'half \& half' situation. At this point the Talmud holds on to the so called 'Rabbis' view' (deduced from the Rabbis' words as part of the Talmud's commitment to their past heritage), that in a natural random process 'half \& half' never occurs.

After going through a few earlier tanaitic sources trying to prove one way or the other regarding 'half \& half' by means of human intention, the final proof is particularly revealing. An earlier tanaitic source is presented, one that deals with the case of a slain body found outside of a city and it is not known who the slayer is. According to biblical law the elders of the city closest to the body (together with priests) perform a certain ceremony that includes breaking a heifer's neck as part of a forgiveness ritual for the people of the closest city that such a dreadful thing happened under their very noses. However, the tanaitic source introduces a case in which 'a slain body is found at exactly the same distance between two cities. ${ }^{\text {' }}$ '

Now, let's embed this tanaitic expression as quoted within the Talmudic web of inferences (which is constructed by holding on to the so called Rabbis' view) and make the following analysis. It is clear that the position of the body falls under the category of unintentional random process, even though the situation results from human action (slaying). Within the abovementioned Talmudic web of inferences it is ontologically impossible for a natural unintentional random process to result in a half $\&$ half' state-of-affairs, therefore the body cannot be exactly between the two cities. Now what would that imply of any human measurement that does find the body to be exactly between the two cities? Clearly it would imply that this measurement was faulty, eliminating the possibility of human beings to create an exact 'half \& half' situation.

${ }^{32}$ This case arises regarding the question what city should perform the required ceremony? In such a case we cannot define a 'closest city'. 
This is the very situation the Talmud finds itself in when the tanaitic expression becomes part of the Talmud's web of inference. Taking the tanaitic words ('a slain body is found at exactly the same distance between two cities ...) as empirically implying a given situation, leads the Talmud, who view 'half \& half' as an impossibility in natural random processes, to the conclusion that 'half \& half' is impossible also in human intentional measurement and activity. This completes the Talmud's relevant web of inferences: 'half \& half' is an ontological impossibility both in natural unintentional situations and in human intentional situations.

Beyond the deep philosophical implications of such a view, the important point is that this perspective is not a reflection of the Talmud's stance, since there was no Talmudic stance regarding human endeavour, and it is not a reflection of any tanaitic opinion, since they saw no problem with the whole issue of 'half \& half'. This perspective is solely a result of the Talmud employing a tanaitic expression, employing a tanaitic fictitious case, without adopting the tanaitic commitment. This tanaitic expression detached from any context and from any earlier commitment placed in the web of inferences holding to the assumption that in random unintentional contexts there can be no 'half \& half' - results in a final novel Talmudic perspective. This traditional mechanism of inserting commitments from past heritage within one's own assertions, without carefully differentiating between the different perspectives, i.e., with deflated scorekeeping, could 'throw' the speaker into a novel perspective, with the trajectory and the end result not always being evident at the starting point.

\section{SUMMARY}

In this paper I tried to explicate the various connections between a theory of meaning, conceptual dynamics and tradition from an inferentialist perspective, taking Brandom as a faithful representative. Holding on to a Brandomian theory of meaning based on his inferentialism I first articulated the types of dynamics that are natural and justified within such a normative structure underlying his theory of meaning. We came up with a determined-type dynamic and a free-type dynamic, both embedded in the normative structure as defining features of it. Brandom's radical pragmatism exemplifies two extremely opposing levels of constraint which result in these two dynamics; determined-type dynamic with 
an infinite level of constraint, and free-type dynamic with zero level of constraint.

The second part of the paper proposed a dynamic which results from tradition as an expression of the close relationship between tradition and conceptual dynamics. Usually we think of tradition as basically standing in opposition to conceptual dynamics, however, I stress the essential role tradition can have in creating such dynamics. One's traditional stance is defined by one's commitments towards past heritage and the degree in which that heritage is embedded within current language. ${ }^{33}$ Of course, tradition embodies a spectrum of possibilities from a slight commitment towards the past to a highly traditional discursive culture in which the past plays a constitutive role in the speaker's present. In order to explain the dynamic resulting from tradition I utilized Brandom's notion of scorekeeping and navigation between speakers and perspectives; concluding that a basic characteristic of tradition in highly traditional discourses is a lack of differentiation between past and present speakers, leading to an inability of true scorekeeping and navigation. This characteristic results in a unique type of dynamic - the tradition-type dynamic.

The tradition-type dynamic fits naturally into the Brandomian structure and is supported by and compatible with Brandomian normativity, though my notion of tradition is very different from that of Brandom's. Brandom's notion of tradition as if one's past heritage stands as a differentiated and defined entity in which a present speaker just navigates and approaches it seems to miss the point.

My notion of tradition and the dynamic that follows from this notion is manifested in highly traditional discourses. Religious traditional discourses such as the Talmud have an additional level of religious commitments which partake in one's web of commitments towards one's past. This level of religious commitment can add to the lack of differentiating one's self identity from past heritage, and to the inability to navigate between past and present. Since tradition and conceptual dynamics are strong features of the Talmud, one of the unique contributions of the Talmud to the philosophy of language is the way it connects between them. In this way the Talmud adds a dimension that is very much lacking in the philosophy of language, that is - the dimension of tradition; in what way does tradition play a role in forming our

${ }^{33}$ Compare: William James 1907: 82-85. 
language and concepts? The inferentialist perspective fits naturally with the Talmudic discourse, although as I show elsewhere this perspective does not cover the full range of phenomena expressed in the Talmudic discourse. However, by reconstructing this Talmudic tradition-type dynamic from within a Brandomian normative stance I propose that it is not only a description of dynamics within tradition but a rational justification of it.

\section{BIBLIOGRAPHY}

Brandom, Robert B. 1994. Making it Explicit (Cambridge: Harvard University Press)

Brandom, Robert B. 2000. Articulating Reasons: An Introduction to Inferentialism (Cambridge: Harvard University Press)

Brandom, Robert B. 2002. Tales of the Mighty Dead: Historical Essays in the Metaphysics of Intentionality (Cambridge: Harvard University Press)

Clausen, Andrea. 2004. How Can Conceptual Content be Social and Normative and at the same time be Objective (Frankfurt-Lancaster: Ontos-Verlag)

Fisch, Menachem \& Benbaji, Yitzhak. 2011. The View from Within: Normativity and the Limits of Self-Criticism (Notre Dame: Notre Dame University Press)

Fodor, Jerry \& LePore, Ernie. 2001. 'Brandom's Burdens: Compositionality and Inferentialism', Philosophy and Phenomenological Research, LXIII: 465-481

James, William. 1907. 'Pragmatism: A New Name for Some Old Ways of Thinking, in Pragmatism and The Meaning of Truth (Cambridge, Massachusetts: Harvard University Press (eighth printing, 1996)

Lycan, William G. 2000. Philosophy of Language: A contemporary Introduction (London and New York: Routledge)

MacFarlane, John. 2003. 'Future Contingents and Relative Truth', The Philosophical Quarterly, 53: 321-336

Putnam, Hilary. 1981. 'Two Conceptions of Rationality', in Reason, Truth and History (Cambridge: Cambridge University Press), pp. 103-126

Rouse, Joseph. 2002. How Scientific Practices Matter: Reclaiming Philosophical Naturalism (Chicago: University of Chicago Press)

Stout, Jeffery. 2002. 'Radical Interpretation and Pragmatism: Davidson, Rorty, and Brandom on Truth', in Radical Interpretation in Religion, Nancy Frankenberry (ed.) (Cambridge: Cambridge University Press), pp. 25-52

Stout, Jeffery. 2007. 'On Our Interest in Getting Things Right: Pragmatism without Narcissism', in New Pragmatists, Cheryl Misak (ed.) (Oxford: Oxford University Press), pp. 7-31

Wittgenstein, Ludwig. 1980. Culture and Value, translated by Peter Winch (Oxford: Basil Blackwell) 